\title{
Socioeconomic gradients in children's cognitive skills: are cross-country comparisons robust to who reports family background?
}

\author{
John Jerrim and John Micklewright \\ Institute of Education, University of London
}

February 2014

\begin{abstract}
$\underline{\text { Abstract }}$
The international surveys of pupil achievement - PISA, TIMSS, and PIRLS - have been widely used to compare socioeconomic gradients in children's cognitive abilities across countries. Socioeconomic status is typically measured drawing on children's reports of family or home characteristics rather than information provided by their parents. There is a well established literature based on other survey sources on the measurement error that may result from child reports. But there has been very little work on the implications for the estimation of socioeconomic gradients in test scores in the international surveys, and especially their variation across countries. In this paper we use the PISA and PIRLS datasets to investigate the consistency of parent and child reports of three common socio-economic indicators (father's occupation, parental education, and the number of books in the family home) across a selection of OECD countries. Our results suggest that children's reports of their father's occupation provide a reliable basis on which to base comparisons across countries in socioeconomic gradients in reading test scores. The same is not true, however, for children's reports of the number of books in the home - a measure commonly used - while results for parental education are rather mixed.
\end{abstract}

Key Words: educational inequality, social mobility, measurement error, PISA, PIRLS.

Contact details: John Jerrim (j.jerrim@ioe.ac.uk) and John Micklewright (j.micklewright@ioe.ac.uk), Department of Quantitative Social Science, Institute of Education, University of London, 20 Bedford Way London, WC1H 0AL

Acknowledgements: We thank the Russell Sage Foundation for funding on a related project which led to the idea for this paper. The work was partly funded by the European Union FP7 GINI project. Helpful comments were made at a GINI workshop at the LSE and by seminar participants at the Institute of Education. We thank Dick Wiggins for his comments on a draft. We would also like to thank the editor and four anonymous referees for their helpful comments. 


\section{Introduction}

There is keen interest in the association of child outcomes with family background. Parents with better education, higher occupations and greater income can invest more in children and provide other stimuli to their development (e.g. Haveman and Wolfe 1995). The international surveys of children's cognitive achievement - the Programme for International Student Assessment (PISA), the Progress in International Reading Literacy Study (PIRLS), and the Trends in International Mathematics and Science Study (TIMSS) - have increased attention on the country variation in these socioeconomic gradients. Countries can be compared, showing whether the gradient in any one country is particularly large, and the impact of differences between countries in institutional structures and policies that may limit disadvantaged children's achievement can be explored (Hanushek and Woessmann 2011).

The information on family background that is used in these analyses is typically collected from the children rather than their parents. A literature drawing on other datasets shows that children may report their parents' and other home characteristics with error (Looker 1989, Koretz 1992, Lien et al. 2001, West et al. 2001, Buchmann 2002). But there has been little consideration of whether inaccurate child reports of family background bias the comparisons across countries of socioeconomic gradients in test scores. Research using the international surveys has either drawn on small scale field trial data simply to illustrate the association between parent and child reports (Adams and Wu 2002, Schulz 2006), or in important work by Kreuter et al. (2010) on the reporting of parental education, has analysed just one country. Although insightful, these investigations do not show the differences across countries and do not compare use of different measures of socioeconomic status (SES).

This paper aims to fill these gaps. Specifically, we address three questions:

1. How does the consistency of parents' and children's reports of three commonly used SES measures vary across OECD countries?

2. Is there an association between this consistency and the children's test scores, suggesting that reporting error is not random - and does the strength of the association vary across countries?

3. Are cross-national comparisons of the SES gradient in test scores robust to whether one uses child or parent reports of the SES? 
In answering these questions, we provide the first analysis of the extent and implication of differences in child and parent reports of SES in a cross-national comparative context.

We consider three measures of SES: parental education, parental occupation, and the number of books in the home. The first two are standard measures. The third has less obvious validity. Evans et al. (2010) see the number of books in the home more as a measure of scholarly culture. But it is a common SES proxy in cross-national research given its presence in all three of PISA, TIMSS and PIRLS as well as other international surveys (Schütz et al. 2008, Machin 2009, Brunello et al. 2012). We do not pursue the issue further here, accepting that - rightly or wrongly - the number of books in the home is a widely used measure of SES. It is beyond our scope to consider the impact of differences in child and parent reports on composite measures of family background, such as the PISA Economic, Social and Cultural Status (ESCS) index. The use of SES measures as separate covariates within regression models remains a common empirical strategy in cross-national research (e.g. Marks 2008, Levels et al. 2008, OECD 2010).

Section 2 describes the data from the surveys we use, PIRLS and PISA, and our methods. PIRLS includes a parental questionnaire, providing information on books in the home to compare with child reports for this measure. PISA has recently collected reports from both parents and children on parental education and occupation for some countries. We assess the extent of parent and child agreement for the three SES measures. We then compare differences across countries in SES test score gradients between regression models using parent reports and models using child reports. Since parent reports may also be subject to error, we cannot be sure that the data reveal the full extent of measurement error in the child reports or its impact. Hence our emphasis is on differences between parent and children reports and the robustness of conclusions: does the switch from child to parent reports make a difference? Section 3 presents results and Section 4 gives conclusions and recommendations. An appendix provides a more technical description of how measurement error may influence cross-national comparisons of SES test score gradients. On-line Supplementary Material gives further information on several details of our analyses.

\section{Data and methods}

Our data are drawn from PIRLS (IEA 2003a) and PISA (OECD 2009a). The former surveys $4^{\text {th }}$ grade (age $9 / 10$ ) children and the latter 15 year olds. The surveys have two stage designs. 
First, schools are sampled with probability proportional to size. In PIRLS, one or two classes are then randomly selected from each school (IEA 2003b), while in PISA a random sample of 35 children is taken. We use data from 2001 and 2006 for PIRLS and 2006 and 2009 for PISA. These provide SES measures reported separately by the study children and by their parents. TIMSS collects information on SES from the children only so we cannot use this survey here. We restrict analysis to OECD member countries.

Both PIRLS and PISA aim to test children's 'functional literacy' - how well they can use the skills examined in 'real life' situations. Children participating in PIRLS sit a one hour test in reading while PISA respondents take a two hour test covering reading, maths and science; we focus on results for reading. ${ }^{1}$ Both surveys summarize children's answers to the test questions into a single score using an item-response model; the intuition is that true ability is unobserved and is estimated from responses to the test. Five 'plausible values' of reading proficiency are generated for each child. Scores are scaled by the organizers of both surveys to have a mean across core participating countries of 500 and a standard deviation of 100. In view of the large volume of data, we use the first of these plausible values throughout our analysis. ${ }^{2}$ We report all our results in units of national z-scores: we subtract the country specific mean from the 'test score', i.e. the first plausible value, and divide by the country specific standard deviation.

PIRLS has always had a parental questionnaire in addition to the child questionnaire. One or two countries do not include the parent survey - England in 2011 and the USA in all rounds - and response by parents is notably low in several other countries, as we show later. PISA administered no questions to parents in 2000 and 2003. But ten OECD countries did so in 2006 and nine in 2009, although there was again substantial non-response that we document below. In both surveys, the most common pattern is for the child's mother to complete the parental questionnaire alone: $70 \%$ of cases in most countries in PISA and $75 \%$ in PIRLS. ${ }^{3}$ Unfortunately, only children - but not parents - in PISA are asked about the number of books. And only parents - but not children - in PIRLS are asked about parental occupation and education. Hence we cannot compare the consistency of child and parent reports between the two surveys for the same SES measure.

\footnotetext{
1 We re-ran a selection of analyses using maths scores. Our conclusions on the robustness of SES gradients to who reports family background were unchanged.

${ }^{2}$ Our estimates of standard errors allow for the clustering of the children within schools. OECD (2009b: 129) note that 'analysing one plausible value instead of five plausible values provides unbiased population estimates'. We experimented with models using each plausible value, applying the BRR replicate weights and averaging the resulting parameter estimates as recommended by the survey organisers. We found very little change in results. ${ }^{3}$ See Supplementary Material D for further information.
} 
Parental Occupation. Children in PISA are asked two free-format questions about both their mother and father and the parental questionnaire in 2006 asked the same questions (Table 1). No information on occupation was asked of parents in 2009. We therefore have 10 countries where parent and child reports of parental occupation can be compared. The respondents' descriptions were converted by the survey organisers into four digit International Standard Classification of Occupation (ISCO) codes. ${ }^{4}$ We recode the data in a similar manner to Marks (2011) giving five social class groupings: high professional, low professional, routine white collar, skilled manual, and semi-skilled or unskilled manual. ${ }^{5} \mathrm{We}$ also comment on results under alternatives, including the occupational status index of Ganzeboom and Treiman (1996). We focus on results for father's occupation; use of mother's occupation gives similar results.

\section{$<$ Table $1>$}

Parental Education. Children in PISA were asked two questions about their mother's and father's education with analogous questions to parents (Table 1). Country specific options were provided corresponding to International Standard Classification of Education (ISCED) levels. ${ }^{6}$ Parents were not asked to discriminate between levels of education below ISCED 3A; a level that implies the parent completed high school in the USA. We therefore combine children's reports of parental education below ISCED level 3A into a single group so we have the same set of five categories for child and parent reports: ISCED level 5A/6, level 5B, level 4, level 3A, below level 3A. For brevity, results are presented for father's education only in the main body of the paper. Results using mother's education are similar and can be found in Supplementary Material B.

Books in the home. We have to switch to PIRLS to investigate our third SES measure. PIRLS is the only international study where information on books in the home is collected from both children and parents. Children are asked a single question and parents are posed a very similar one (Table 1). A diagram in the child questionnaire accompanies each category of books. For example, the diagram for 26-100 books shows a full bookcase with four

\footnotetext{
${ }^{4}$ See www.ilo.org/public/english/bureau/stat/isco/isco88/publ4.htm. Our Supplementary Material C gives further information.

${ }^{5}$ We use Stata code written by Hendrickx (2004). We include the small number of children with parents reported as farm workers in the semi-skilled or unskilled manual category.

${ }^{6}$ The ISCED classification is described at http://www.uis.unesco.org/Education/Pages/international-standardclassification-of-education.asp.
} 
shelves. Children in PIRLS reporting this information are younger than children reporting parental education and occupations in PISA. If we find that books in the home is the least consistently reported SES measure when comparing child and parent reports, this could be due to younger children being less able to provide reports of home and family characteristics than are older children (see Looker 1989) rather than to the number of books in the home being particularly difficult for children to estimate. ${ }^{7}$

For all three SES measures, there are limits to the assessment of measurement error in children's reports by comparing child and parent responses. First, the information provided by parents may also contain error, including as a result of proxy reporting e.g. the mother reporting the father's education (see Supplementary Material D). We expect this to be especially important for the number of books and least important for occupation. In practice, we can therefore only investigate the consistency of child and parent reports and not the extent to which children report the 'truth'.

Second, there is the problem of complex family structures. The PISA questionnaire instructs children to provide information for the parent or person 'like a mother or father to you... whom you spend the most time with'. The parental questionnaire simply asks about 'the mother and the father of the student'. This could result in child reports referring to one person while parental reports refer to someone else, weakening the association between the two variables. The extent of this problem could also differ across countries. The issue is considered in Supplementary Material D.

Finally, there is the practical matter of missing reports of SES, either from children or, more commonly, from parents - notably due to non-response. Table 2 shows the extent of this problem in the PISA and PIRLS data for 2006. For father's occupation and education (PISA) there is at least one report missing for over a quarter of the sample in about half the countries. The figure varies considerably so that information is complete for father's occupation in only $48 \%$ of cases in Denmark but $92 \%$ in Korea. The problem is driven by the figures for missing parental reports and its extent increases the incentive for researchers to use the child SES reports, an incentive that is already high given the few countries administering the parental questionnaire. Missing information is less common for books in the home in PIRLS, although there are very large numbers of missing parental reports in a small number of countries: $30 \%$ or more in the Netherlands, Spain, New Zealand, Scotland, and England. Recall also that no parental questionnaire is issued in the USA.

\footnotetext{
${ }^{7}$ There is also a small difference in the question on books posed to parents and children, although we assume this is not important in practice.
} 
Parents and children who fail to report SES may be systematically different. Table 3 presents mean reading test scores for children with the parent SES report missing (left panel) or the child report missing (right panel) minus the mean for children with complete information (both reports present), measured in national z-scores. The data are for 2006. All figures are negative: children with missing parent or child reports of SES have lower average test scores and by amounts that are not trivial. The extent of this selectivity varies across countries.

$<$ Table $3>$

In principle, we could take the selectivity due to the missing data into account. But the relevant methods rely on strong assumptions. Consequently, we undertake a 'complete case' analysis, restricting our analysis to those children where both parent and child reports are available (cases in Table 2, column 2). Supplementary Material A discusses the issue of missing data in more detail and how it may influence our results. Reassuringly, we find little evidence that use of the complete case sub-sample leads to biases in our comparison of SES gradients across countries.

\section{Methods $s^{8}$}

Question 1. We document for each SES measure the frequency with which parents and children report the same category of the variable concerned ('percentage agreement'). Each variable has five categories. This measure of consistency does not take into account that parents and children may agree simply by chance. We therefore also present estimates of Cohen's Kappa, a measure of 'inter-rater reliability' that adjusts for chance agreement. ${ }^{9}$

Question 2. Following Kreuter et al. (2010), we consider whether children whose SES reports agree with those of their parents (i.e. same category reported) have test scores that differ on average from those of other children. This provides an indication of whether

\footnotetext{
${ }^{8}$ All analyses are conducted with Stata 13 .

${ }^{9}$ Brennan and Prediger (1981) discuss the assumptions behind use of the Kappa statistic, notably: (i) reporters operate independently; (ii) categories are independent, exhaustive and mutually exclusive.
} 
reporting errors are random with respect to children's test scores (i.e. whether $\operatorname{cov}(v, Y)=0$ in the terminology of the Appendix).

Question 3. We use a linear regression model to estimate the SES gradients in test scores for each country. The dependent variable is the child score on the PISA or PIRLS reading test, with SES - defined by one of our three measures - the covariate of interest. We include controls for children's age, gender, immigrant status, and the interaction of immigrant status with SES. Dummies for missing information for controls are included - all cases included in the regressions have complete information on the SES measure in question. This particular specification has been chosen for consistency with the existing literature (Schütz et al. 2008). Formally, we estimate the model:

$T_{i j}=\alpha+\boldsymbol{\beta}^{\prime} . \boldsymbol{S} \boldsymbol{E} \boldsymbol{S}_{\boldsymbol{i}}+\gamma_{1} \cdot$ Gender $_{i}+\gamma_{2 .}$ Age $_{i}+\gamma_{3} . \operatorname{Imm}_{i}+\gamma_{\mathbf{4}}^{\prime} \cdot \mathbf{S E S} * \operatorname{Imm}_{i}+\epsilon_{i j}$

( $i=$ child, $j=$ school)

where $T$ is the child's reading test score and SES is the measure of socio-economic status. Gender is a dummy variable (reference group = girl), Age measures child age in months, and Imm is a dummy variable indicating the child is either a first or second generation immigrant (reference group = country native). Since $S E S$ is a categorical variable it is entered as a vector of dummy variables (reference group = semi/unskilled manual). When using the books variable, we combine the bottom two categories (0-10 and 11-25 books) to form the reference group due to the sparse number of observations in the lowest category. The parameter estimate for the most advantaged group (e.g. high professional occupation) provides our estimate of the SES gradient in test scores. In other words, for each measure our primary focus is the gap in children's test scores between the most advantage and least advantaged group. We check the robustness of results to this choice below.

We estimate the model twice for each country for each SES measure, once using child reports of the variable (education, occupation, or books) and once using parent reports. The same complete case sub-sample is used for both the child and parent report models. Comparison of the results from the two sets of regressions shows whether the cross-country pattern of SES gradients is robust to who reports SES - child or parent.

\section{Results}


Agreement between parents and children

Table 4 shows percentage agreement between parent and child reports and the Kappa statistics for inter-rater reliability. ${ }^{10}$ Kappa values can vary between -1 (perfect disagreement) and +1 (perfect agreement). To aid interpretation, we follow the Landis and Koch (1977) rules of thumb on levels of agreement (all our Kappa statistics are positive): 0.01-0.20 'slight', $0.21-0.40$ 'fair', 0.41-0.60 'moderate', 0.61-0.80 'substantial', and 0.81-0.99 'almost perfect'. Two features of the results are of interest: (a) whether agreement between children and parents differs among SES measures, and (b) the extent of variation across countries for each measure.

$<$ Table $4>$

For books in the home, most of the Kappa statistics are less than 0.2 , indicating only 'slight' agreement. The percentage of children reporting the same category of books as parents averages just $40 \%$ and reaches $50 \%$ just in one country (Turkey). There is also modest variation across countries, with Kappa statistics ranging from 0.14 to 0.34 .

Father's education shows more consistency between parent and child reports. Most Kappa statistics exceed 0.40, suggesting 'moderate' agreement, and the percentage of children reporting the same category as their parents is everywhere above $50 \%$, averaging $63 \%$. However, there is quite a lot of variation across countries, with Kappa statistics ranging from 0.36 to 0.76 .

The results for father's occupation are the most encouraging. Consistency between parent and child reports tends to be higher than for the other SES measures - Kappa statistics typically exceed 0.60 , indicating 'substantial' agreement, and percentage agreement averages $71 \%$ with only limited variation across countries. We also computed correlations between parent and child reports using the continuous occupational status index of Ganzeboom and Treiman (1996). Values were reasonably high, averaging 0.69 , and again showed only moderate variation across countries. This is in-line with Looker (1989) and Lien et al. (2001), who found that child reports of parental occupation tend to be more consistent than child reports of parental education.

\footnotetext{
${ }^{10}$ We also estimated Kappa values that give more weight to disagreement of increased gravity (cells further away from the leading diagonal). The pattern of results was unchanged.
} 
Agreement between parents and children is best for parental occupation and least good for books in the home. ${ }^{11}$ This may reflect the younger age of children in PIRLS than in PISA, although Vereecken and Vandegehuchte (2003) find children only a little older than in PIRLS giving reports on parental occupation that agreed well with those of parents. Or it may reflect the difficulty in estimating numbers of books, whether for children or adults, implying parental as well as child error is to be expected.

\section{Relationship between the consistency of SES reports and the child's test score}

Do children whose SES reports agree with those of their parents have higher test scores? The answer indicates whether reporting error is random with respect to the response variable. Figure 1 shows the difference in mean reading achievement, in national z-scores, between children who agree with parents and other children. The two-letter country labels are given in Table 4. We subtract the mean for children who disagree from the mean from those who agree: positive values show that children providing consistent reports have higher test scores.

\section{$<$ Figure $1>$}

We start with father's occupation. The $95 \%$ confidence interval includes zero for 9 out of 10 countries indicating no significant difference in mean reading scores. Moreover, crossnational variation is modest, with values typically less than 0.15 national standard deviations. This again provides encouraging signs of the validity of children's reports of father's occupation, and the consistency of cross-national estimates based upon this measure.

The differences in means are notably larger for father's education. They are all positive and in almost every case statistically significant at the 5\% level. Children who agree with parents score on average approximately 0.2 of a national standard deviation higher on the PISA reading test. This extends the conclusion of Kreuter et al. (2010) for just Germany to a much larger set of countries. There is modest variation across countries - Denmark (DK) is the median and we cannot reject the hypothesis that the difference in mean scores here is the same as in most other countries.

The pattern for books in the home is similar to that for father's education. Children

\footnotetext{
${ }^{11}$ We checked results for the five countries (Italy, Iceland, Poland, Germany and New Zealand) with data for parents and children on all three SES measures; books in the home still showed the least consistency between parent and child reports, and father's occupation the most.
} 
who report the same books category as parents on average have higher test scores. Crossnational variation is again moderate, with the confidence intervals typically overlapping. Outliers include England (GB(E)), where children who agree with parents score on average 0.35 of a national standard deviation more than those who disagree.

\section{Robustness of SES gradients to the choice of child or parent reports}

Does the pattern of differences in SES score gradients across countries depend on the choice of child or parents reports on which to base the SES measure?

Father's Occupation. We estimate the model in equation (1), entering father's occupation as a series of dummy variables. We summarise the SES gradient by the estimated coefficient on highest level of occupation. This measures the average difference in reading score between children with 'high professional' fathers and children with 'semi/unskilled manual' fathers, the base category, controlling for other variables in the model.

Figure 2 shows estimates on the horizontal axis when using child reports of father's occupation and on the vertical axis when using parent reports. The gradient varies greatly across countries, from under 0.5 to over 1.0 national standard deviations. However, data points are all close to the 45 degree line $(r=0.94)$. This close correspondence means that the pattern and size of differences in SES gradients across countries is robust to the choice of child or parental reports. We checked the sensitivity of results to use of (i) the Ganzeboom and Treiman (1996) index and (ii) the ISCO nine major groups. The correlation between SES gradients based on child and parent reports remained around 0.9 .

$<$ Figure $2>$

Father's Education. We again enter dummy variables in the regressions (in place of those for father's occupation). Our SES gradient is the average difference in points scored between those reporting a low level of father's education, below ISCED level 3A- did not complete high school - and those reporting a high level, ISCED 5A and above - university degree. Estimates using child reports are on the horizontal axis in Figure 3 and those using parent reports on the vertical axis. We now use data for both 2006 and 2009 and append the last digit of the survey year to the two-letter country code (e.g. 'DE6' is Germany in 2006).

\section{$<$ Figure $3>$}


A striking feature is that 17 out of 18 data points sit above the 45 degree line: estimates are larger with the parent reports. This shows that the Kreuter et al. (2010) finding with just German PISA data holds much more widely. If the goal is to estimate the SES gradient within any one country, then use of data on father's education reported by children will lead to an underestimate. Bias is typically about 0.1 of a standard deviation but is larger in some countries, notably New Zealand. However, the similarity in apparent bias across most countries means that the correlation between the two sets of estimates of SES gradient is quite high $(r=0.89)$. Consequently, conclusions on differences across countries in the SES gradient are moderately robust to whether the child or the parent reports are used.

Books in the home. Our SES gradient is the average difference in test scores between children with more than 200 and 0 to 25 books in the home, controlling for the other variables in the model (Figure 4). There are many more data points than in Figures 2 and 3 as information for books in the home is drawn from PIRLS which has parent reports for many more countries than PISA.

\section{$<$ Figure $4>$}

The correlation between estimates of the SES gradient based on parent reports and those based on child reports is clearly lower than for the other SES measures $(r=0.37)$. Moreover, there is no obvious pattern of an upward or downward change when switching between the two: there is considerable scatter around the 45 degree line. There are outlier countries with a large change in results, e.g. England, Italy and Greece. The cross-country pattern of differences in SES gradients is not that robust to the switch between child reports and parent reports. It is difficult to have confidence in finer details of the pattern, particularly when trying to identify countries where SES gradients in scores are atypically large or small. For example, England has been cited in the literature as having a high gradient (e.g. Schütz et al 2008), which is only true with the child reports.

The results in Figures 2-4 refer to average differences in scores, controlling for other characteristics, between children in the top and bottom categories of each SES variable. We check the robustness of results to selection of other pairs of categories. For example, we can redefine the SES gradient as the average difference, conditional on the controls, between scores in the top category and an intermediate category. In each case we re-compute the correlation coefficient for the sets of country SES gradients based on child and parent reports. 
We do this for all possible pairs of categories for each SES measures (Table 5). The circled figures refer to the correlations reported earlier for Figures 2-4.

$<$ Table $5>$

Most of the correlations are high for father's occupation. The lowest figures, 0.75 and 0.77 , are for gradients estimated using adjacent categories of occupation. The pattern of variation across countries in the SES gradients is broadly robust both to whether the child or the parent reports the information on father's occupation and to the selection of the occupational groups to compare.

For father's education, results are more sensitive to the selection of the categories to compare. Low correlations occur when comparing children in ISCED level $3 \mathrm{~A}$ group to the other categories: the value is below 0.50 in each case and is only just positive for the level 3/below $3 \mathrm{~A}$ comparison. One possible explanation is that the questions asked to parents and children were not identical, with the main discrepancy occurring around the ISCED level 3A category (see Section 2). Alternatively, it could just be that this is a problematic category for children to report. Otherwise, correlations are mostly in the range of 0.70 or above, suggesting that results in Figure 3 are reasonably robust. However, in most cases, the data points in analogous graphs (not shown) no longer clearly sit above the 45 degree line: the pattern of attenuation in estimates of SES gradients based on child reports seen in Figure 3 when comparing top and bottom categories is no longer found.

For books in the home, the correlations range from 0.51 to a low of 0.07 , with all but one of the six figures below a modest 0.40 . This re-enforces our earlier finding: crossnational comparisons of SES gradients in test score based on books in the home are quite sensitive to whether the child or the parent provides the information on the number of books.

\section{Conclusions}

We have investigated the agreement between child and parent reports of SES measures (questions 1 and 2) in international surveys of children's learning achievement and have analysed whether estimates of differences across countries in SES gradients in reading test scores are robust to which report is used (question 3). Using data from PISA and PIRLS, we have considered SES measures based on parental occupation, parental education, and the number of books in the home. This is an important exercise given the reliance on the child 
reports in much research with these two surveys and with the third such survey, TIMSS. Analysts either must use child reports to construct SES variables (TIMSS and early rounds of PISA) or may choose to do so in order to maximise the number of countries analysed and the number of cases with complete information (PIRLS and, especially, later rounds of PISA).

There is substantial agreement in PISA data between parents' reports of father's occupation and those of their 15 year old children. In only one country out of 10 did average test scores differ significantly between children reporting the same category of occupation and those reporting a different one, indicating a lack of systematic reporting bias linked to reading ability. Differences across countries in SES gradients in test scores seem robust to whether child or parent reports are used for parental occupation. Although we would like these findings replicated for more countries, we think they imply that children's reports of parental occupation provide a reliable basis with which to analyse cross-national differences in SES test score gradients.

We are less positive about books in the home. There is much lower agreement between parents and children than for parental occupation, although we cannot tell to what extent this is due to the data relating to a younger group of children, $9 / 10$ year olds. In all but one of the 24 countries in our PIRLS data, less than $50 \%$ of children report the same category of books in the home as their parents. Children reporting a different category have average reading scores that are almost always significantly lower than those reporting the same category, implying that reporting error is not random. Estimates of cross-national differences in the SES test score gradient are quite sensitive to who provides the information, parent or child, with some countries moving dramatically in the international rankings (e.g. England). We advise caution with the use of this variable.

The appropriate conclusion for parental education is less obvious. Although consistency of parent and child reports is reasonable overall, the picture for some countries is a concern. The pattern of cross-country differences in SES gradients is fairly robust to the choice of parent or child reports when comparing the most and least advantaged groups, but not all such comparisons are so encouraging. The evidence available does not seem strong enough for us to either clearly reject or support use of this SES measure.

These findings point to at least two directions for future research. First, we have restricted our examination to OECD countries and it would be useful to extend the analysis to the middle income countries that are increasingly covered by the international surveys of children's learning achievement. Second, offspring reports of parental characteristics are a common feature of other international studies, such as the European Social Survey (ESS), the 
Programme for International Assessment of Adult Competencies (PIAAC), the European Union Statistics on Income and Living Conditions (EU-SILC), and the Survey of Health, Ageing and Retirement in Europe (SHARE). These other studies ask respondents to recall information on their parents' occupation and education level and/or books in the home when the respondent was a teenager or even younger. Little is currently known about how well such information is reported and whether this induces bias into estimates of SES gradients in other lifetime outcomes (e.g. occupational attainment). An investigation of possible reporting error in such surveys seems an important priority.

Information on family background is a key component in any survey of school children. Collecting that information from children only is likely to remain an attractive lowcost option. Our recommendation to the PISA, PIRLS and TIMSS survey organisers is that further efforts be made to validate the quality of child reports of SES measures, encompassing all participating countries. Researchers using the data to investigate SES differences in test scores should draw confidence from some of our findings while proceeding with caution given others. 


\section{Appendix. Measurement error and cross-national comparisons of SES gradients}

What difficulties do measurement errors in SES variables cause in international comparisons of SES gradients in children's test scores? For ease of illustration, we assume a bivariate linear model:

$$
Y_{i}=\alpha+\beta \cdot X_{i}^{*}+\varepsilon_{i}
$$

where $Y_{i}$ is the test score of child $i, X_{i}^{*}$ is the child's true (perfectly measured) SES, and $\varepsilon_{i}$ is a random term. The Ordinary Least Squares (OLS) regression estimate of $\beta$ is given by:

$$
\hat{\beta}=\frac{\operatorname{cov}\left(X_{i}^{*}, Y_{i}\right)}{\operatorname{var}\left(X_{i}^{*}\right)}
$$

where 'cov' and 'var' refer to sample values. Assume that we observe not $X_{i}^{*}$, but a misreported measure, $X_{i}$ :

$$
X_{i}=X_{i}^{*}+v_{i}
$$

where $v_{i}$ is the measurement error. The standard treatment of measurement error assumes that it is 'classical': $X_{i}$ is just a noisy measure of SES, with $v_{i}$ uncorrelated both with the true value $X_{i}^{*}$, and with $\varepsilon_{i}$ (and hence $Y_{i}$ ). In this case, suppressing the individual sub-script $i$ from now on, the OLS estimate becomes:

$$
\hat{\beta}=\frac{\operatorname{cov}\left(X^{*}, Y\right)}{\operatorname{var}\left(X^{*}\right)+\operatorname{var}(v)}
$$

The estimate of the SES gradient is biased downwards in absolute size - the textbook case of 'attenuation bias'. The proportional bias in the probability limit of the estimate of $\beta$ depends on the ratio of the population variances, $\operatorname{VAR}(v) / \operatorname{VAR}\left(X^{*}\right)$, the so-called noise-to-signal ratio (Cameron and Trivedi 2005:903).

If children report SES in each country with 'classical' error, then estimates of the SES test score gradients based on these reports will all be biased downwards. Whether the 
estimated pattern of differences across countries in these gradients is biased depends on the cross-country variation in noise-to-signal ratios. Were these all the same, estimates of the relative differences in the SES gradients would be unaffected. The gradient estimate in each country would be too low, but conclusions of the type 'the SES gradient in Country A is twice that in Country B' would not be altered. In this case, one could assess appropriately the relative differences across countries despite the error in the data. However, there seems little reason to expect this situation to prevail, especially when relevant institutional details, e.g. education systems, vary across countries.

The more fundamental objection is the reliance on the assumption that error is 'classical', uncorrelated with the true value of SES or with the child's test score. In their major survey of measurement error, Bound et al. (2001) note that this assumption tends to 'reflect convenience rather than conviction' and argue that 'the possibility of non-classical measurement error should be taken much more seriously by those who analyze survey data'. Mason et al. (1976) discuss the issue with specific reference to children's reports of SES measures. Kreuter et al. (2010) draw upon cognitive theory of response behaviour to argue that children who score highly on achievement tests are more likely to report parental SES measures correctly. Using a follow-up of the PISA 2000 German sample containing SES information from parents, they find some evidence of this for parental education. They then shed doubt on the assumption that reporting error is uncorrelated with the true SES value: children with the highest value of parental education as reported by their parents, a university degree, can only provide the same information or under-report, while those with the lowest value reported by parents, no qualifications, can only provide the same information or overreport. What are the implications of 'non-classical' measurement error? Kreuter et al. (2010) note the expression for the OLS estimator becomes:

$$
\hat{\beta}=\frac{\operatorname{cov}\left(X^{*}, Y\right)+\operatorname{cov}(v, Y)}{\operatorname{var}\left(X^{*}\right)+\operatorname{var}(v)+\operatorname{cov}\left(v, X^{*}\right)}
$$

Consider the single country setting. If, following Kreuter et al., more able children provide better reports, then $\operatorname{cov}(v, Y)<0$, resulting in a downward impact on the estimate of $\beta$ through the numerator of (4). And if, as just discussed, $\operatorname{cov}\left(v, X^{*}\right)<0$, an upward impact comes through the denominator. In this situation the estimated SES gradient in test scores may not be attenuated. Rather, it depends on the exact values of $\operatorname{cov}(v, Y), \operatorname{cov}\left(v, X^{*}\right)$ and $\operatorname{var}(v)$. The direction of bias in the estimated SES gradient becomes an empirical question. 
What about the cross-national setting, with the goal of comparing SES gradients across countries? Unlike with 'classical' error, the form of the bias in the estimate of $\beta$ is not a multiplicative adjustment factor. So even in the very unlikely circumstances of all countries having the same values of $\operatorname{cov}(v, Y), \operatorname{cov}\left(v, X^{*}\right)$, and $\operatorname{var}(v)$, bias in the ratio of the SES gradient estimates for any pair of countries would result. Even in this special case, a conclusion that 'the SES gradient in Country A is twice that in Country B' could not be drawn safely.

To this point we have considered regression with a single explanatory variable. But in practice researchers often estimate SES gradients controlling for other individual or family characteristics or school-level variables. This further complicates cross-country comparison. Returning to the case of 'classical' error, attenuation bias increases, relative to that with a single explanatory variable, the greater is the correlation between the true value of the mismeasured variable and the other variables included in the regression (Bound et al. 2001: equation (5), Wooldridge 2002: 75). This correlation may well vary across countries. For example, the correlation between SES and school type will be stronger in countries with selective school systems. So even in this simpler case of 'classical' error and in the unlikely event that noise-to-signal ratios are everywhere the same, the cross-country pattern of SES gradients in test scores estimated with a mis-measured SES variable is likely to be misleading.

In the main body of the paper, we (i) compare how well child and parent reports of SES agree, (ii) how their differences correlate with test scores, and (ii) how estimates of SES gradients in scores obtained with child reports compare with those obtained with parent reports. We have purposely framed this investigation with discussion of children's reporting errors, rather than measurement errors, as we cannot rule out that parents could also report SES with error, rather than providing the true values, $X^{*}$. We would expect errors in parent reports to be smaller, especially when the SES measures refer to their own individual characteristics. But the possibility of parental error means that the focus of our empirical investigation is more on the robustness of results: how do results differ when we switch between use of child and parent reports of SES? 


\section{References}

Adams, R. and Wu, M. (2002) PISA 2000 Technical Report, Paris: OECD

Bound, J., Brown, C., and Mathiowetz, N. (2001) 'Measurement error in survey data' in J. Heckman and E. Leamer (eds.) Handbook of Econometrics, vol. 5, Amsterdam: Elsevier.

Brennan, R. and Prediger, D. (1981) 'Coefficient Kappa: some uses, misuses, and alternatives'. Educational and Psychological Measurement 41(3): 687 - 699.

Brunello, G., Weber, G., and Weiss, C. (2012), 'Books are forever: early life conditions, Education and Lifetime Income'. IZA Discussion Paper 6386.

Buchmann, C. (2002) 'Measuring family background in international studies of education: conceptual issues and methodological challenges' in A. Porter and A. Gamoran (eds.) Methodological Advances in Cross-National Surveys of Educational Achievement, Washington DC: National Academy Press.

Cameron, C. and Trivedi, P. (2005) Microeconometrics, Cambridge: Cambridge University Press.

Evans, M., Kelley J., Sikora J., and Treiman, D. (2010) 'Family scholarly culture and educational success: books and schooling in 27 nations', Research in Social Stratification and Mobility, 28 (2): 171-97.

Ganzeboom, H. and Treiman, D. (1996) 'Internationally comparable measures of occupational status for the 1988 international standard classification of occupations', Social Science Research, 25: 201-239.

Haveman, R. and Wolfe, B. (1995). 'The determinants of children's attainments: a review of methods and findings.' Journal of Economic Literature 33(4): 1829-78.

Hanushek, E. and Woessmann L. (2011) 'The economics of international differences in educational achievement' in E. Hanushek, S. Machin and L. Woessmann (eds.) Handbook of the Economics of Education, volume 3, North-Holland.

Hendrickx, J. (2004) 'ISKO: Stata module to recode 4 digit ISCO-88 occupational codes', Boston College Department of Economics.

IEA (2003a) PIRLS 2001 user guide for the international database, International Study Center: Boston College.

IEA (2003b) PIRLS 2001 technical report, International Study Center: Boston College.

Koretz, D. (1992) Evaluating and validating indicators of mathematics and science education, RAND note N-2900-NSF. Santa Monica, CA: RAND.

Kreuter, F. Eckman, S. Maaz, K. and Watermann, R. (2010) 'Children's reports of parents' education level: does it matter whom you ask and what you ask about?', Survey Research Methods, 4(3): 127-138. 
Landis, J. and Koch, G. (1977) 'The measurement of observer agreement for categorical data', Biometrics, 33 (1): 159-174.

Levels, M; Dronkers, J. and Kraaykamp, G. (2008) 'Immigrant Children's Educational Achievement in Western Countries: Origin Destination, and Community Effects on Mathematical Performance', American Sociological Review, 73: 835 - 853.

Looker, D. (1989) 'Accuracy of proxy reports of parental status characteristics', Sociology of Education, 62 (4): 257-276.

Lien, N. Friestad, C. and Klepp, K. (2001) 'Adolescents' proxy reports of parents' socioeconomic status: how valid are they?', Journal of Epidemiology and Community Health, 55: 731-737.

Machin, S. (2009) 'Inequality and education' in W. Salverda, B. Nolan, and T. Smeeding (eds.) The Oxford Handbook of Economic Inequality. Oxford: Oxford University Press.

Marks, G. (2008) ‘Are Father's or Mother's Socioeconomic Characteristics More Important Influences on Student Performance? Recent International Evidence.' Social Indicators Research 85(2): 293-309.

Marks, G. (2011) 'Issues in the Conceptualisation and Measurement of Socioeconomic Background: Do Different Measures Generate Different Conclusions?' Social Indicators Research 104:225-251

Mason, W., Hauser, R. M., Kerckhoff, A. C., Poss, S. S., \& Manton, K. (1976). 'Models of response error in student reports of parental socioeconomic characteristics' in W. H. Sewell, R. M. Hauser, and D. L. Featherman (eds.), Schooling and achievement in American society (pp. 443-519). New York: Academic Press.

OECD (2009a) PISA 2006 technical report, Paris: OECD

OECD (2009b) PISA data analysis manual: SPSS second edition, Paris: OECD

OECD (2010) PISA 2009 results: overcoming social background - volume II, Paris: OECD

Schulz, W. (2006) 'Measuring the socio-economic background of students and its effect on achievement in PISA 2000 and PISA 2003', Annual Meetings of the American Educational Research Association. San Francisco (April 7-11, 2005).

Schütz G., Ursprung, H. and Woessmann, L. (2008) 'Education policy and equality of opportunity' Kyklos, 61 (2): 279-308.

Vereecken C., Vandegehuchte A. (2003) 'Measurement of parental occupation: Agreement between parents and their children' Archives of Public Health, 61: 141-9.

West, P., Sweeting, H. and Speed, E. (2001) 'We really do know what you do: a comparison of reports from 11 year olds and their parents in respect of parental economic activity and occupation', Sociology, 35 : 539-59 
Wooldridge, J. (2002) Econometric Analysis of Cross Section and Panel Data, Cambridge MA: The MIT Press. 


\section{Table 1: Questions on family background in PISA and PIRLS}

\section{Occupation (PISA)}

Questions to the children (parents were asked analogous questions):

What is your [mother's / father's] main job? (e.g. school teacher, cook, sales manager)

- Please write in the job title

What does your [mother / father] do in his main job? (e.g. teaches high school students)

- Please use a sentence to describe the kind of work he does or did in that job

Education (PISA) [phrases in brackets illustrate the country specific options for the USA]

Questions to the children:

What is the <highest level of schooling > completed by your [mother/father]?

- ISCED level 3A [She completed grade 12]

- ISCED level 3B/3C [N/A]

- ISCED level 2 [She completed grade 9]

- ISCED level 1 [She completed grade 6]

- She did not complete ISCED level 1 [She did not complete grade 6]

Does your [mother/father] have any of the following qualifications?

- ISCED level 6 [Masters, doctoral, or professional degree such as medicine]

- ISCED level 5A [Bachelor degree - a 4 year college degree]

- ISCED level 5B [Associate degree -2 year degree from a community college]

- ISCED level 4 [Vocational or technical certificate/diploma after high school]

Question to the parents:

Does the child's [mother/father] have any of the following qualifications?

- ISCED level 5A/6

- ISCED level 5B

- ISCED level 4

- ISCED level 3A

Books in the home (PIRLS)

Question to the child:

About how many books are there in your home? (Do not count magazines, newspapers, or your school books)

- None or very few (0-10 books)

- Enough to fill one shelf (11-25 books)

- Enough to fill one bookcase (26-100 books)

- Enough to fill two bookcases (101-200 books)

- Enough to fill three or more bookcases (more than 200)

Question to the parents:

About how many books are there in your home? (Do not count magazines, newspapers or children's books.)

- $0-10$ books

- 11-25 books

- 26-100 books

- 101-200 books

- More than 200 books 
Table 2. Parental and child reports of family background (PIRLS and PISA, 2006)

\begin{tabular}{|c|c|c|c|c|c|c|c|}
\hline & & 1 & 2 & 3 & 4 & 5 & 6 \\
\hline & Country & $\begin{array}{r}\text { Sample } \\
\text { size }\end{array}$ & $\begin{array}{r}\text { Parent and } \\
\text { child report } \\
\text { present } \\
(\%)\end{array}$ & $\begin{array}{r}\text { Child } \\
\text { report } \\
\text { missing } \\
(\%) \\
\end{array}$ & $\begin{array}{r}\text { Parent } \\
\text { report } \\
\text { missing } \\
(\%) \\
\end{array}$ & $\begin{array}{r}\text { Parent and } \\
\text { child report } \\
\text { missing } \\
(\%)\end{array}$ & $\begin{array}{r}\text { Total } \\
(\%)\end{array}$ \\
\hline \multirow{10}{*}{$\begin{array}{l}\text { Father's } \\
\text { Occupation }\end{array}$} & Korea & 5176 & 92 & 1 & 4 & 2 & 100 \\
\hline & Poland & 5547 & 86 & 5 & 5 & 5 & 100 \\
\hline & Turkey & 4942 & 84 & 1 & 6 & 8 & 100 \\
\hline & Italy & 21773 & 79 & 2 & 17 & 2 & 100 \\
\hline & Portugal & 5109 & 74 & 4 & 16 & 6 & 100 \\
\hline & Germany & 4891 & 64 & 8 & 18 & 9 & 100 \\
\hline & Luxembourg & 4567 & 62 & 5 & 25 & 7 & 100 \\
\hline & New Zealand & 4823 & 58 & 4 & 29 & 8 & 100 \\
\hline & Iceland & 3789 & 57 & 4 & 35 & 4 & 100 \\
\hline & Denmark & 4532 & 48 & 8 & 33 & 11 & 100 \\
\hline \multirow{10}{*}{$\begin{array}{l}\text { Father's } \\
\text { Education }\end{array}$} & Korea & 5176 & 93 & 2 & 4 & 1 & 100 \\
\hline & Poland & 5547 & 93 & 3 & 3 & 2 & 100 \\
\hline & Turkey & 4942 & 88 & 2 & 10 & 1 & 100 \\
\hline & Portugal & 5109 & 78 & 3 & 17 & 2 & 100 \\
\hline & Italy & 21773 & 77 & 2 & 20 & 2 & 100 \\
\hline & Germany & 4891 & 69 & 7 & 18 & 7 & 100 \\
\hline & Iceland & 3789 & 59 & 3 & 34 & 4 & 100 \\
\hline & Luxembourg & 4567 & 59 & 7 & 28 & 6 & 100 \\
\hline & New Zealand & 4823 & 57 & 7 & 27 & 9 & 100 \\
\hline & Denmark & 4532 & 55 & 3 & 37 & 5 & 100 \\
\hline \multirow{21}{*}{$\begin{array}{c}\text { Books in the } \\
\text { home }\end{array}$} & Slovakia & 5337 & 95 & 1 & 3 & 0 & 100 \\
\hline & Belgium (Flemish) & 4552 & 95 & 2 & 4 & 0 & 100 \\
\hline & Italy & 3581 & 94 & 2 & 4 & 0 & 100 \\
\hline & Poland & 4854 & 93 & 4 & 3 & 0 & 100 \\
\hline & Slovenia & 5337 & 93 & 2 & 5 & 0 & 100 \\
\hline & Austria & 5067 & 92 & 3 & 5 & 0 & 100 \\
\hline & Denmark & 4001 & 91 & 2 & 6 & 0 & 100 \\
\hline & Sweden & 4394 & 90 & 3 & 7 & 1 & 100 \\
\hline & Luxembourg & 5101 & 89 & 1 & 10 & 0 & 100 \\
\hline & Hungary & 4086 & 89 & 2 & 9 & 1 & 100 \\
\hline & France & 4404 & 87 & 5 & 7 & 1 & 100 \\
\hline & Norway & 3837 & 85 & 7 & 7 & 1 & 100 \\
\hline & Belgium (French) & 4552 & 84 & 6 & 9 & 1 & 100 \\
\hline & Canada & 20565 & 81 & 4 & 14 & 1 & 100 \\
\hline & Germany & 7899 & 80 & 7 & 10 & 4 & 100 \\
\hline & Iceland & 3673 & 73 & 2 & 23 & 2 & 100 \\
\hline & Netherlands & 4156 & 67 & 1 & 31 & 1 & 100 \\
\hline & New Zealand & 6256 & 60 & 3 & 33 & 3 & 100 \\
\hline & Spain & 4094 & 60 & 2 & 35 & 2 & 100 \\
\hline & Scotland & 3775 & 51 & 1 & 47 & 2 & 100 \\
\hline & England & 4036 & 46 & 1 & 52 & 2 & 100 \\
\hline
\end{tabular}

Note: unweighted data. Percentages do not always add to 100 due to rounding. Results for occupation and education refer to PISA. Results for books in the home refer to PIRLS. 
Table 3. Difference in mean reading scores between children with missing SES information and those with complete information (PISA and PIRLS 2006)

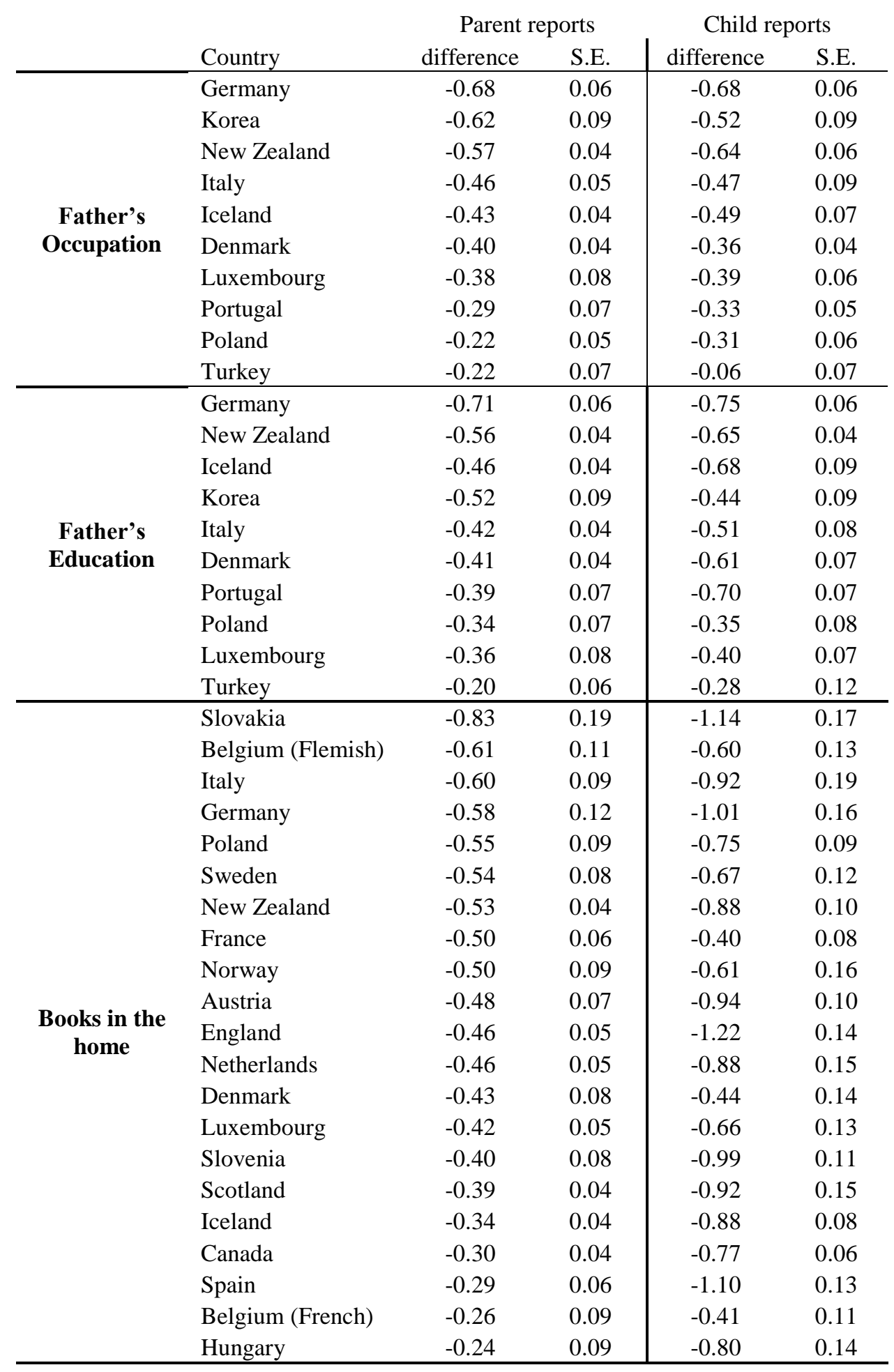

Note: we subtract the mean score for children with complete information from the mean for children with missing information. Figures reported in national z-scores. Final student weights applied. Results for occupation and education refer to PISA. Results for books in the home refer to PIRLS. 
Table 4. Percentage agreement between parent and child reports (PISA and PIRLS)

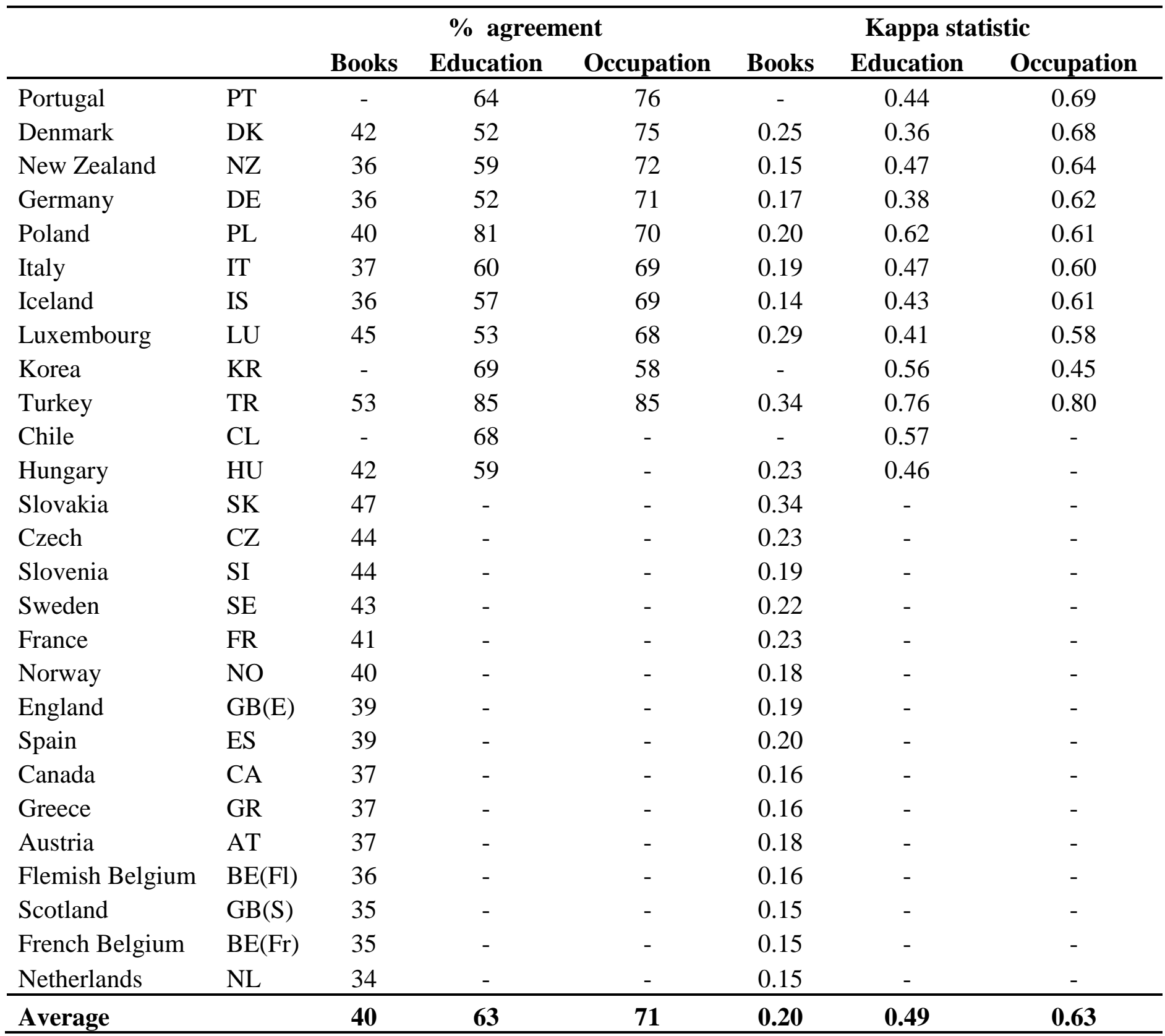

Note: if data are available from more than one year (books in 2001 and 2006 and father's education in 2006 and 2009) we show the unweighted average of the figures for the two years. Calculations are based on unweighted data. The averages across all countries are unweighted figures. Results for occupation and education refer to PISA. Results for books in the home refer to PIRLS. 
Table 5. Correlations between country estimates of SES gradients in reading test scores based on parent and child reports: the impact of changing the comparison group

(a) Father's occupation

\begin{tabular}{lccccc} 
Comparison group & $\begin{array}{l}\text { High } \\
\text { professional }\end{array}$ & $\begin{array}{l}\text { Low } \\
\text { professional }\end{array}$ & $\begin{array}{l}\text { Routine white } \\
\text { collar }\end{array}$ & $\begin{array}{l}\text { Skilled } \\
\text { manual }\end{array}$ & $\begin{array}{l}\text { Semi/unskilled } \\
\text { manual }\end{array}$ \\
\hline High professional & - & & & & \\
Low professional & 0.86 & - & & & \\
Routine white collar & 0.80 & 0.77 & - & - & - \\
Skilled manual & 0.92 & 0.94 & 0.91 & 0.75 & \\
Semi/unskilled manual & 0.94 & 0.95 & 0.90 & &
\end{tabular}

(b) Father's education

\begin{tabular}{lccccc} 
Comparison group & ISCED 5A & ISCED 5B & ISCED 4 & ISCED 3A & Below 3A \\
\hline ISCED 5A & - & & & & \\
ISCED 5B & 0.68 & - & & & \\
ISCED 4 & 0.82 & 0.72 & - & & \\
ISCED 3A & 0.47 & 0.23 & 0.46 & - & - \\
ISCED Below 3A & 0.89 & 0.52 & 0.88 & 0.11 &
\end{tabular}

(c) Books in the home

\begin{tabular}{lcccc} 
Comparison group & $>200$ books & $101-200$ books & $26-100$ books & $0-25$ books \\
\hline$>200$ books & - & & & \\
$101-200$ books & 0.33 & - & & \\
$26-100$ books & 0.51 & 0.07 & - & - \\
$0-25$ books & 0.37 & 0.27 & 0.39 & - \\
\hline
\end{tabular}

Notes: SES gradients in reading test score have been estimated using every possible pair of categories within each of the measures. The categories in the first column are the changing comparison categories. For each SES measure, the figures give the correlations between the two sets of estimates of gradients, one based on child reports of SES and one on parent reports. For example, the circled figure in panel (a) refers to the gradients estimated using the 'high professional' and 'semi/unskilled manual' groups (that is, the difference in average reading test scores between these two categories, controlling for other variables in the regression model). The circled figures in each panel give the correlations for the scattergrams in Figures 2 and 4. Final student weights applied. Results for occupation and education refer to PISA. Results for books in the home refer to PIRLS. 
Figure 1. Difference in average test scores between children reporting the same SES category as their parents and those who do not (PISA and PIRLS 2006)

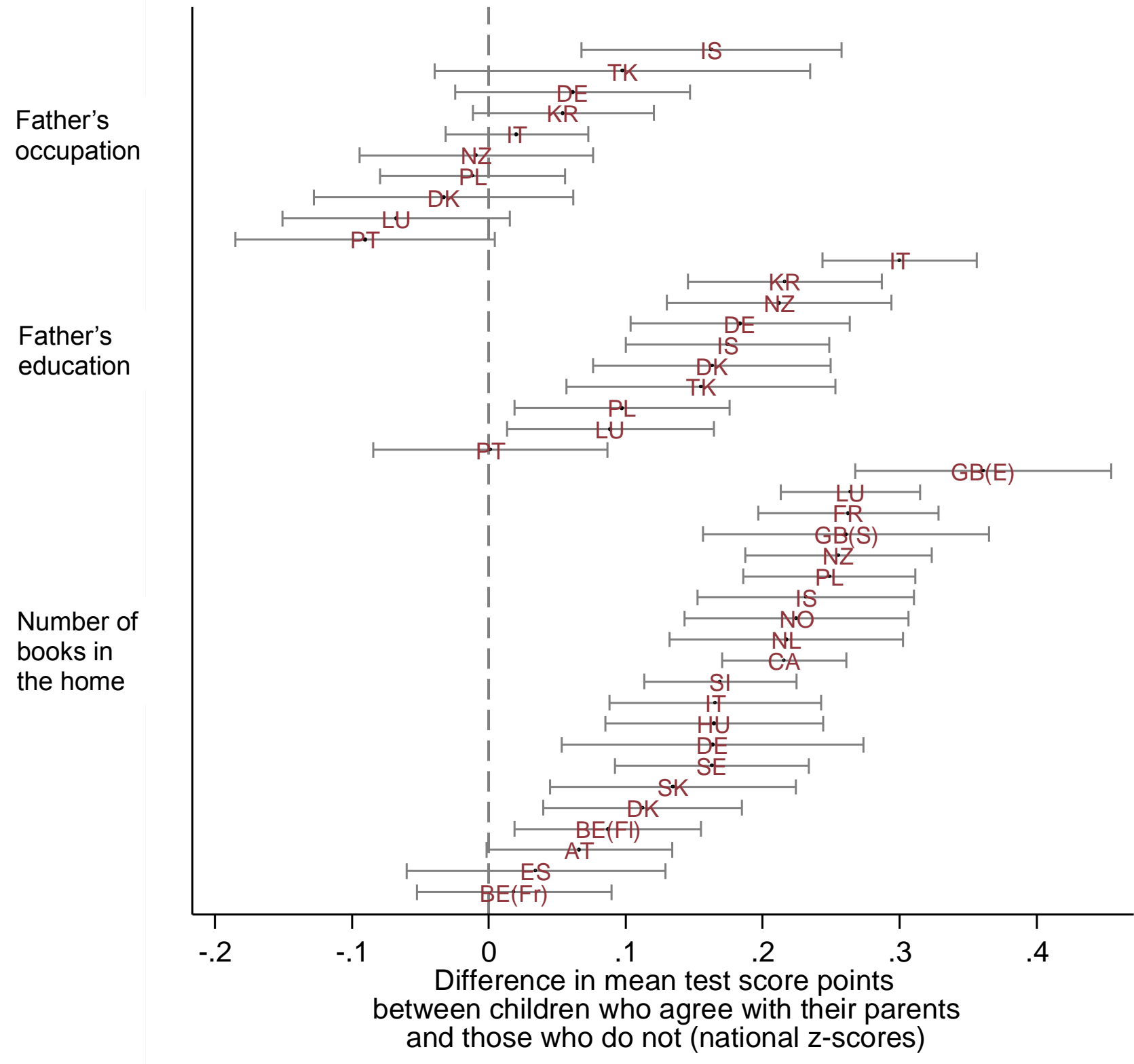

Notes:

The graph shows the difference in average reading test scores between children who report the same SES category as their parents and those who do not (subtracting the latter from the former). All figures refer to national standard deviations. The thin line running through the country name shows the estimated $95 \%$ confidence interval. Final student weights applied. Results for occupation and education refer to PISA. Results for books in the home refer to PIRLS. 
Figure 2. Estimated SES gradient in child test scores - comparison of results based on parent reports and child reports of father's occupation (PISA)

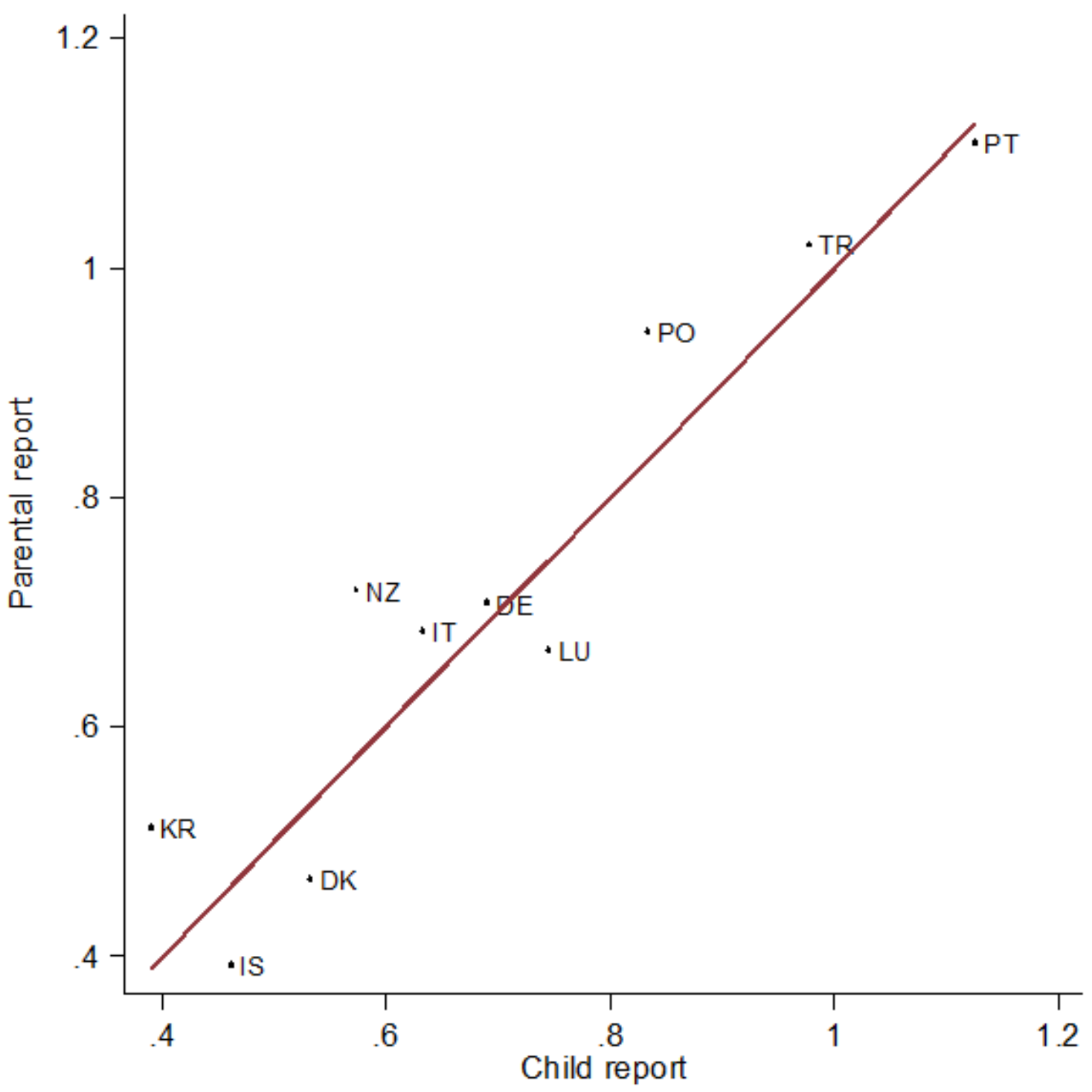

Notes: the graph shows the difference in average reading test scores, controlling for other variables included in the regression model, between children with the highest ('high controller') and lowest ('semi/unskilled manual') levels of father's occupation. The units are national standard deviations. The correlation between the two sets of estimates is 0.94 . Two letter country abbreviations are given in Table 4 . The data refer to 2006. Final student weights applied. 
Figure 3. Estimated SES gradient in child test scores - comparison of results based on parent reports and child reports of father's education (PISA)

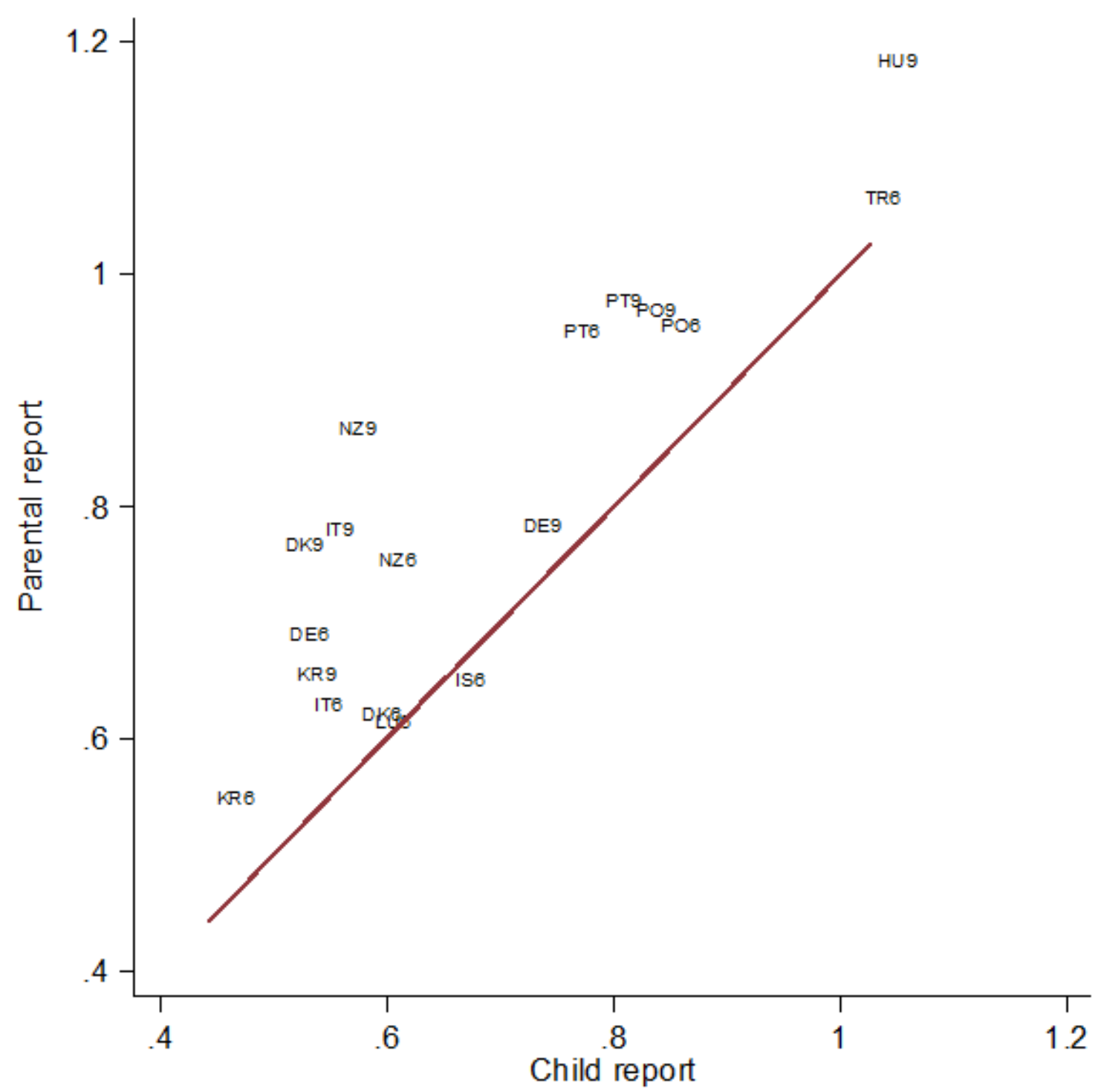

Notes: the graph shows the difference in average reading test scores, controlling for other variables included in the regression model, between children with the highest (ISCED 5A+) and lowest (ISCED below 3A) levels of father's education. The units are national standard deviations. The correlation between the two sets of estimates is 0.89 . Two letter country abbreviations are given in Table 3; the digit ending the label shows the year to which the data point refers (' 6 ' $=2006,{ }^{\prime} 9$ ' $=2009$ ). Final student weights applied. 
Figure 4. Estimated SES gradient in child test scores - comparison of results based on parent reports and child reports of books in the home (PIRLS)

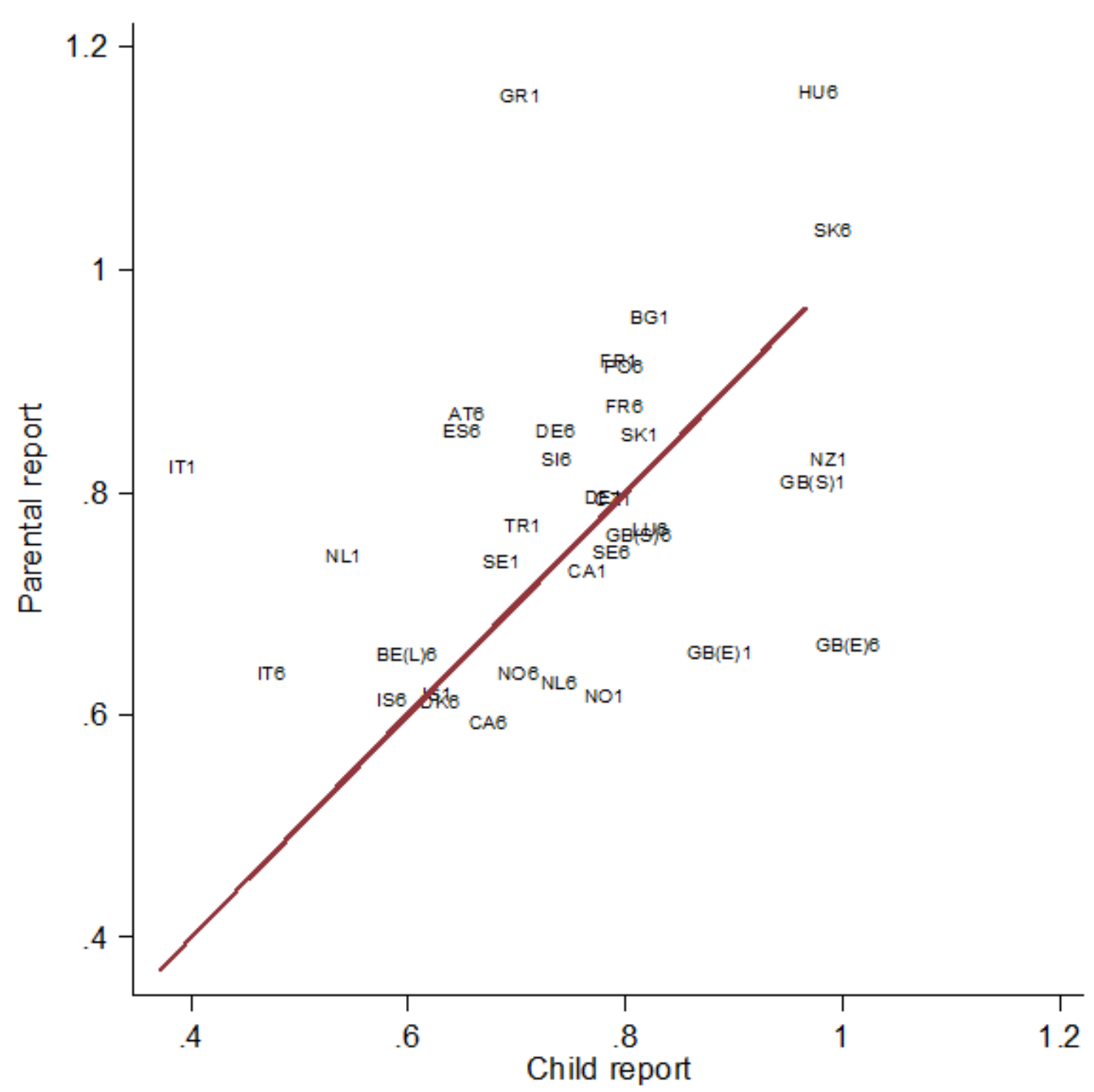

Notes:

Notes: the graph shows the difference in average reading test scores, controlling for other variables included in the regression model, between children with the highest (more than 200 books) and lowest ( $0-25$ books) reported levels of books in the home. The units are national standard deviations. The correlation between the two sets of estimates is 0.37 . Two letter country abbreviations are given in Table 3 ; the digit ending the label shows the year to which the data point refers (' 1 ' $=2001$, ' 6 ' $=2006$ ). Final student weights applied. 